\title{
Study of a Two Steps Process for the Valorization of PVC-Containing Wastes
}

\author{
A. Castro $\cdot$ C. Carneiro $\cdot$ C. Vilarinho $\cdot$ \\ D. Soares $\cdot$ C. Maçães $\cdot$ C. Sousa $\cdot$ F. Castro
}

Received: 29 December 2011/ Accepted: 29 October 2012

(C) Springer Science+Business Media Dordrecht 2012

\begin{abstract}
The presence of organic compounds in wastes, namely polymer based compounds, is considered a potential relevant source of energy. However, the presence of polyvinyl chloride (PVC) in their composition, causes recycling problems when a thermal process is considered for the wastes treatment [1] preventing its use on processes which the main goal is the energy recovery (Zevenhoven et al. in Fuel 81:507-510, 2002; Kim in Waste Manag 21:609-616, 2001). A possible solution should consider a first step for chlorine removal, through a pyrolysis process previously to a subsequent thermal treatment, for energetic valorization. The present work assesses a possible process for treating PVC-containing wastes in an environmentally
\end{abstract}

\author{
A. Castro $(\bowtie) \cdot$ C. Carneiro \\ Center for Waste Valorization (CVR), Guimarães, Portugal \\ e-mail: acastro@cvresiduos.pt \\ C. Carneiro \\ e-mail: ccarneiro@cvresiduos.pt
}

A. Castro $\cdot$ C. Vilarinho $\cdot$ D. Soares - F. Castro

Mechanical Engineering Department, Centre for Mechanical

and Materials Technologies (CT2M), University of Minho,

Guimarães, Portugal

C. Vilarinho

e-mail: candida@dem.uminho.pt

D. Soares

e-mail: dsoares@dem.uminho.pt

F. Castro

e-mail: fcastro@dem.uminho.pt

C. Maçães · C. Sousa

Endutex-Textile Coatings, SA, Guimarães, Portugal

e-mail: cesar.macaes@endutex.pt

C. Sousa

e-mail: celia.sousa@endutex.pt friendly way. It is based on the effective de-chlorination of PVC-containing wastes through a pyrolysis process at low temperature before the carbonaceous residue (chlorine free fraction) being subjected to a subsequent thermal treatment for energetic valorization with the production of a synthesis gas (syngas). In the end of the process concentrated hydrochloric acid or other chlorine solutions and a syngas, with high energetic potential are obtained. The synthesis gas produced can be used in turbines or gas engines, replacing the gases obtained from fossil non-renewable resources. The validation of the proposed treatment of PVC-containing wastes in pilot scale has also been performed.

Keywords Pyrolysis - Thermal degradation . PVC-containing waste $\cdot$ Energetic valorization

\section{Introduction}

Poly (vinyl chloride) (PVC) is the most commonly polymer used in the industry presenting a wide range of applications in different sectors of activity. However, its high chlorine content causes considerable environmental problems, constraining the employment of the traditional recycling and waste treatment procedures or technologies. As consequence of its versatility and range of applications, the annual PVC world production reaches 22 million tons [4] with high amounts of PVC-containing wastes being consequently, generated. Although these wastes exhibit high energetic potential, for both energy and alternative fuels production, the main fraction is disposed on landfills, with high environmental impact caused by phthalate and heavy metals leach out. 
Polymers can be recycled by three different methods: mechanical recycling, chemical recycling and energy recovery [5-8]. The mechanical recycling involves physical processes for the separation of the plastic wastes mixtures such as crushing, melting or granulation. Chemical or feedstock recycling include processes that assures the depolymerization of plastics, such as the pyrolysis and the hydrolysis, where the thermal and the chemical decomposition, respectively [4]. Energy recovery may takes place in the form of electricity, heat or steam, through the burning of the waste, as in the case of incineration [6,8].

Pyrolysis is one of the applied techniques for energetic valorization and is defined as a process of irreversible chemical modification of compounds, under the action of heat and in the absence of oxygen, causing thermal degradation [1]. The reactions involved in this process are normally endothermic and the characteristics of the obtained products are function of the waste composition and of several operating factors, such as the temperature, the pressure and the reaction or residence time in the reactor.

Several authors [2-4, 9-12] consider pyrolysis as the most promising technique for energy recovery from PVCcontaining wastes, through the thermal degradation of the chlorine molecule. PVC pyrolysis involves significant cross-linked reactions that lead to the formation of polyaromatic structures (possibly chlorinated) and a carbonaceous residue (char) [13]. Thus, it is possible to break down this molecule, allowing the chlorine recovery in the form of hydrochloric acid or chloride [14], with potential economic benefits.

However, the presence of poly(vinyl chloride) in the composition of wastes, confines their management by thermal valorization processes as consequence of environmental concerns and corrosion of the equipments. In fact, the high levels of chlorine are responsible for the formation of hydrochloric acid, chlorine gas and dioxins with high environmental impact [15]. Therefore, the application of a previous thermal pyrolysis treatment, removing the chlorine from the PVC-containing wastes shall be a suitable step previously to an energy recovery process. After the elimination of chlorine, the pyrolysis products can then be used as fuels, preventing the production of hazardous products in the subsequent step [16].

Based on thermogravimetric analysis, it is assumed that the degradation of PVC occurs between 200 and $400{ }^{\circ} \mathrm{C}$ $[2,17]$. At $250{ }^{\circ} \mathrm{C}$, the decomposition of PVC is already initiated, reaching a maximum at approximately $300{ }^{\circ} \mathrm{C}$. At $350{ }^{\circ} \mathrm{C}$ the amount of chlorine present in PVC waste is less than 0.1 which means that, at this temperature, $99.5 \%$ of the whole chlorine has already been released [2]. At the end of the process of chlorine removal, a residual amount of chlorine remains on the waste [14].
The $\mathrm{C}-\mathrm{Cl}$ bonds in the structure of $\mathrm{PVC}$ have a relatively lower binding energy than the $\mathrm{C}-\mathrm{C}$ and $\mathrm{C}-\mathrm{H}$ bonds, which justifies that the bonds of chlorine are the first to be broken, thus starting the thermal degradation of PVC. The de-chlorination of PVC is a free radicals chain reaction therefore requiring low activation energy to start, occurring at low temperatures $[9,11,18,19]$.

The present work aims the development of a new twostep procedure for the treatment of PVC-containing wastes, enabling its energetic valorization. Several pyrolysis experiments were performed at low temperatures in order to study the thermal de-chlorination process of the PVC molecule (first step) and the subsequent energetic valorization of the chlorine-free remaining fraction (second step). The treatment results in the production of chlorine products and of a synthesis gas with high energetic potential, which shall be used to replace natural gas or other fossil fuels. The validation of the proposed treatment at a pilot scale has also been performed in the aim of the present research.

\section{Experimental Work}

\section{Kinetic Model Development}

In order to determine the relationship between the rate of PVC de-chlorination and the temperature of the thermal treatment, TGA tests have been performed in a DTA/TGA 2960 TA instruments equipment for different temperatures and under an inert atmosphere (helium).

These experiments have been conducted up to 5 different maximum temperatures: $250,275,300,325$ and $400{ }^{\circ} \mathrm{C}$, with a heating rate of $10^{\circ} \mathrm{C} / \mathrm{min}$, until the final temperature is reached. At each of the selected temperatures, a stage of $360 \mathrm{~min}$ has been done to verify the reaction evolution. Heat flux (weight corrected heat flow in $\mathrm{W} / \mathrm{g}$ ) and weight of sample, have been continuously recorded. The amount of sample used in the DTA/TGA tests ranged from 29.8 to $44.9 \mathrm{mg}$.

The material used for the DTA/TGA tests was a commercial pure PVC powder (\#VICIR S 950), a vinyl chloride homopolymer $\left(\mathrm{C}_{2} \mathrm{H}_{3} \mathrm{Cl}\right)$, produced by a suspension polymerization process and with $56.7 \%$ chlorine.

For the analysis of the chemical composition of the commercial PVC used in the experiments and the carbonaceous residues formed after the pyrolysis and the energetic valorization step, a TruSpec Elemental Determinator, model TruSpec CHN (Leco), with a burn time of $452 \mathrm{~s}$ and a Philips Analytical sequential X-ray fluorescence (XRF) Spectrometer model X'Unique II, were used. To determine the lower heating value (LHV) or the lower calorific value 
(LCV) a calorimeter, model AC500 Calorimeter (Leco) was used.

\section{Pilot Scale for Validation of the Process}

The experiments at the pilot plant were conducted using a real sample of PVC-containing waste from a Northern Portugal textile industry. Table 1 presents the composition of the selected PVC-containing waste. As can be seen, the main constituent corresponds to PVC (45\%), with the second position being held by the plasticizer $(29.1 \%)$. Presently this type of material is classified as hazardous waste due to the high levels of chlorine and is land filled.
Table 1 PVC-containing waste composition

\begin{tabular}{ll}
\hline Component & $\%(\mathrm{w} / \mathrm{w})$ \\
\hline PVC & 45 \\
Plasticizer $^{\mathrm{a}}$ & 29 \\
Polyester & 14 \\
Calcium carbonate $\left(\mathrm{CaCO}_{3}\right)$ & 6 \\
Expansion agent & \\
Soybean oil & 4 \\
Titanium dioxide $\left(\mathrm{TiO}_{2}\right)$ & 1 \\
\end{tabular}

a 1,2-Benzenedicarboxylic acid

b Azodicarboamide
Fig. 1 Scheme of the pilot scale used for the tests, with the reactor $(A)$, the column for fixation of chlorine released $(B)$, the column for second phase $(C)$, outlet tubes of gases on the cover of the reactor $(D)$, the temperature controller $(E)$, vacuum pump $(F)$, thermocouple indicator $(G)$ and bench support $(H)$

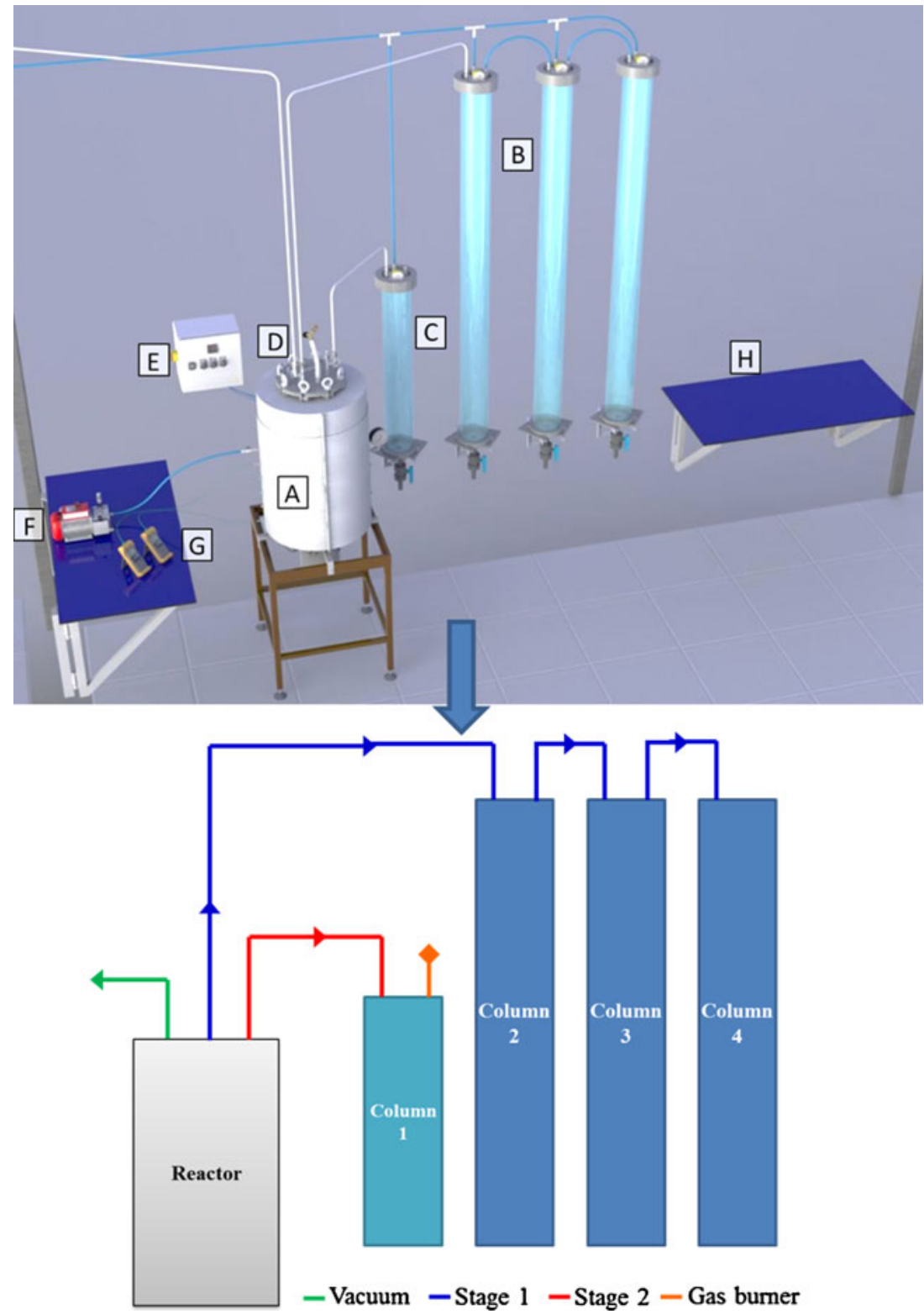




\section{Pilot Plant}

In order to validate the experimental data obtained at the DTA/TGA tests and laboratory experiments, a scale up was undertaken with the construction of a pilot scale plant. The plant (Fig. 1) includes, as main components, a reactor where the pyrolysis (stage 1) and the energetic valorization (stage 2) processes occur, and three liquid columns where the fixation of the released chlorine proceed in the form of $\mathrm{HCl}$ (hydrochloric acid), $\mathrm{CaCl}_{2}$ (calcium chloride) or $\mathrm{NaCl}$ (sodium chloride), in function of the aqueous solution used.

A small column was added (column $\mathrm{C}$ in Fig. 1) to test the burning of the gas in two situations, one in which the gas is directly burned when it exits from the reactor and another one in which the gas is burned after passing through an aqueous solution removing possible oil vestiges that might clog the burner, adversely affecting the burning process (Fig. 3).

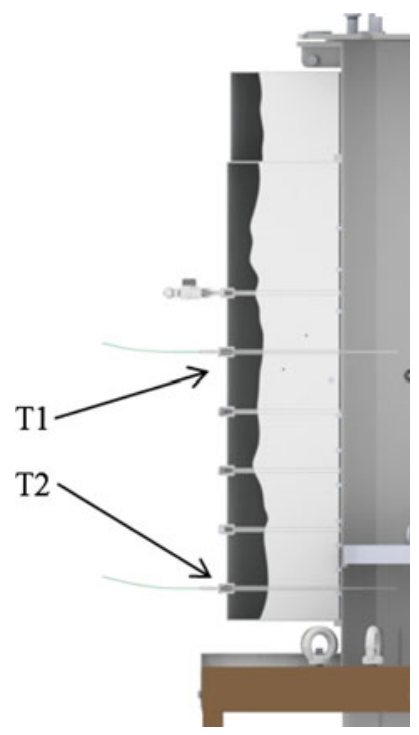

Fig. 2 Detail of the two zones of thermocouples input (1 and 2)
The reactor is heated by three electrical heating elements $(2.5 \mathrm{~kW} \times 3)$, able to reach temperatures of about $950{ }^{\circ} \mathrm{C}$.

Throughout the whole process, temperature and pressure are monitored and controlled. Thermocouples allow the temperature measurement in real time in two distinct zones of the reactor (Fig. 2). The zone near the grid (T2), where waste is supported, and the other closer to the gas exit (T1). The pressure measurement is performed in the reactor and in each column, using pressure gauges.

As it is mandatory that the pyrolysis process occur in an anoxic environment (i.e., in the absence of oxygen or other oxidizing agent), all the air is sucked before starting the experiments, producing a vacuum atmosphere inside the reactor ( -0.5 bar).

It was dimensioned a safety valve (Fig. 3) for the reactor cover that opens when the pressure reaches a critical value (1.5 bar above atmospheric pressure) which can jeopardize the integrity of the installation.

This plant was carefully projected as complete tests could be performed without undesirable stops occur due to clogging caused by residue formation during process. An expedite and quick cleaning process was also foreseen.

As it is being mentioned, the first phase of the process (pyrolysis at low temperature) release gas, mud and oils, the last two in very small amounts. Since the original purpose of the process is to remove the chlorine of PVCcontaining waste, all the products resulting from the process represent a high risk of corrosion to installation materials.

Stainless steels are usually applied due to its mechanical properties [20], surface aspect and good resistance to corrosion and oxidation caused by the action of atmospheric or chemical agents [21], and in the case of austenitic steels, they are capable to maintain these properties at high temperatures [20]. Considering this, the stainless steel AISI 304 was the chosen material for the reactor and for most of the components mounted on the connection setup.

Due to the high demand of temperature ranges, isolation and sealing joints were also carefully addressed,
Fig. 3 Cover of the reactor with gas burner $(A, C)$ gas burner on the column $(B)$ and safety valve $(D)$
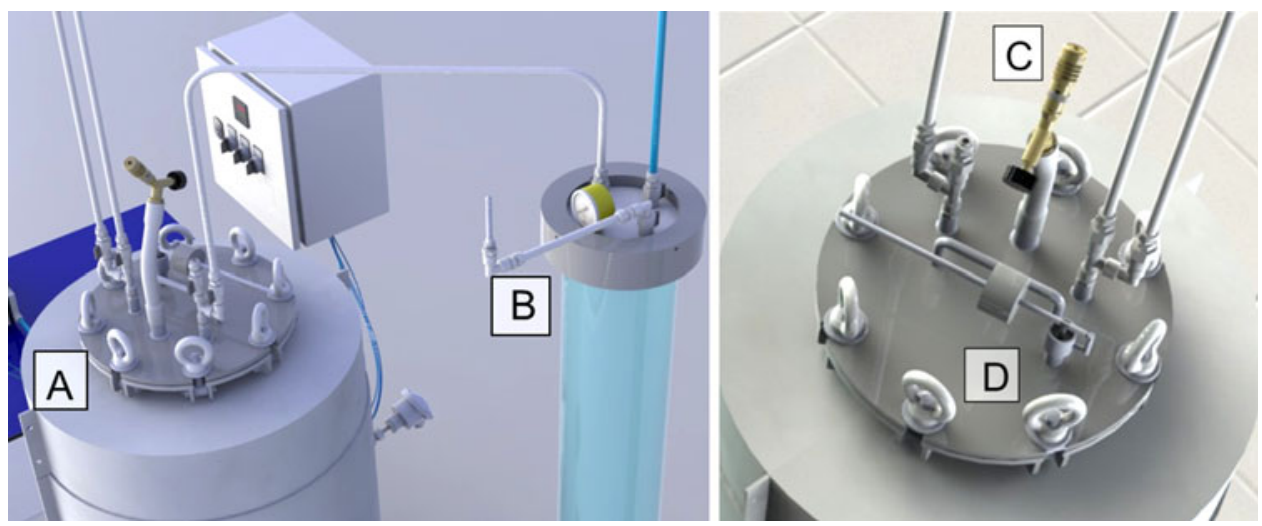
supporting, not only the temperature, but also the high pressures inside the reactor. In this case it was applied ceramic fiber blanket (Fiberfrax ${ }^{\circledR}$-Unifrax) as isolating agent and for the sealing joints graphite with a middle stainless steel mesh, were used.

The material chosen for the columns was acrylic or Poly(methyl methacrylate) mainly because of its reasonable toughness, rigidity and transparency [22]. This allows the visualization of the solution inside the column and all the visual changes that might occur, as well as monitoring the decomposition of material, through the gas bubbling on the aqueous solutions.

\section{Results and Discussion}

Kinetic Model for the Thermal Decomposition of PVC

The kinetic model was developed with the results of the DTA/TGA experiments realized to five different temperatures, in Fig. 4 is presented the curve obtained at $400{ }^{\circ} \mathrm{C}$. The kinetic model was developed, considering only the data obtained when the temperature was stabilized.

Through the analysis of the DTA/TGA curve presented in Fig. 4, it is possible to conclude that the release of chlorine starts at $256 \pm 2{ }^{\circ} \mathrm{C}$. No mass release was detected until the starting temperature of the PVC thermal decomposition cycle is achieved.

With all the experimental data obtained, a multivariate regression of $\ln (\rho)$ was deduced as function of $1 / \mathrm{T}$ and $\ln$ ( $\mathrm{HCl} \mid$ ). A very good fit has been obtained for all experimental points after the desired temperature has been reached, with the exception of the experiments up to $400{ }^{\circ} \mathrm{C}$, in which the decomposition rate is much higher than expected. Nevertheless, even for this case, the points obtained during heating cycle, until the temperature of $340{ }^{\circ} \mathrm{C}$ gave a good correlation with the proposed model. Considering this, the kinetic model has been calculated only for points where temperature was lower than $340{ }^{\circ} \mathrm{C}$. It is assumed that, for higher temperatures, as shown in the curve of DTA/TGA in Fig. 4, other reactions might occur.

The obtained model is [23]:

$\ln \rho=31.3-\frac{16100}{T}+1.020 \ln [\mathrm{HCl}] \quad$ with $\mathrm{r}^{2}=0.9912$

This allows considering that the decomposition of PVC reaction $\left(\mathrm{C}_{2} \mathrm{H}_{3} \mathrm{Cl} \rightarrow \mathrm{HCl}+\mathrm{C}_{2} \mathrm{H}_{2}\right)$ is a first order reaction with activation energy of $133,800 \pm 760 \mathrm{~J} / \mathrm{mol}$, a value very close to ones obtained in others works reported [9].

The statistical treatment of the obtained results led to the establishment of the kinetics of thermal de-chlorination, indicating that, almost all chlorine is removed from the pure PVC, at the temperature of $340{ }^{\circ} \mathrm{C}$.

Through the carbonaceous residue analysis (Table 2), it was possible to conclude that this trial had a removal rate of $99.9 \%$ (w/w) of chlorine. The de-chlorinated fraction obtained at $340{ }^{\circ} \mathrm{C}$ is mainly constituted by carbon presenting only a residual chlorine content of $0.07 \%$.

The carbonaceous residue, previously obtained during the de-chlorination test was subjected to the DTA/TGA analysis at temperatures up to $500{ }^{\circ} \mathrm{C}$ (Fig. 5), in which it was identified an important loss of weight that occur at approximately $491{ }^{\circ} \mathrm{C}$. This reaction is instantaneous, promoting the
Fig. 4 DTA/TGA curve obtained for PVC sample heated up to $400{ }^{\circ} \mathrm{C}$

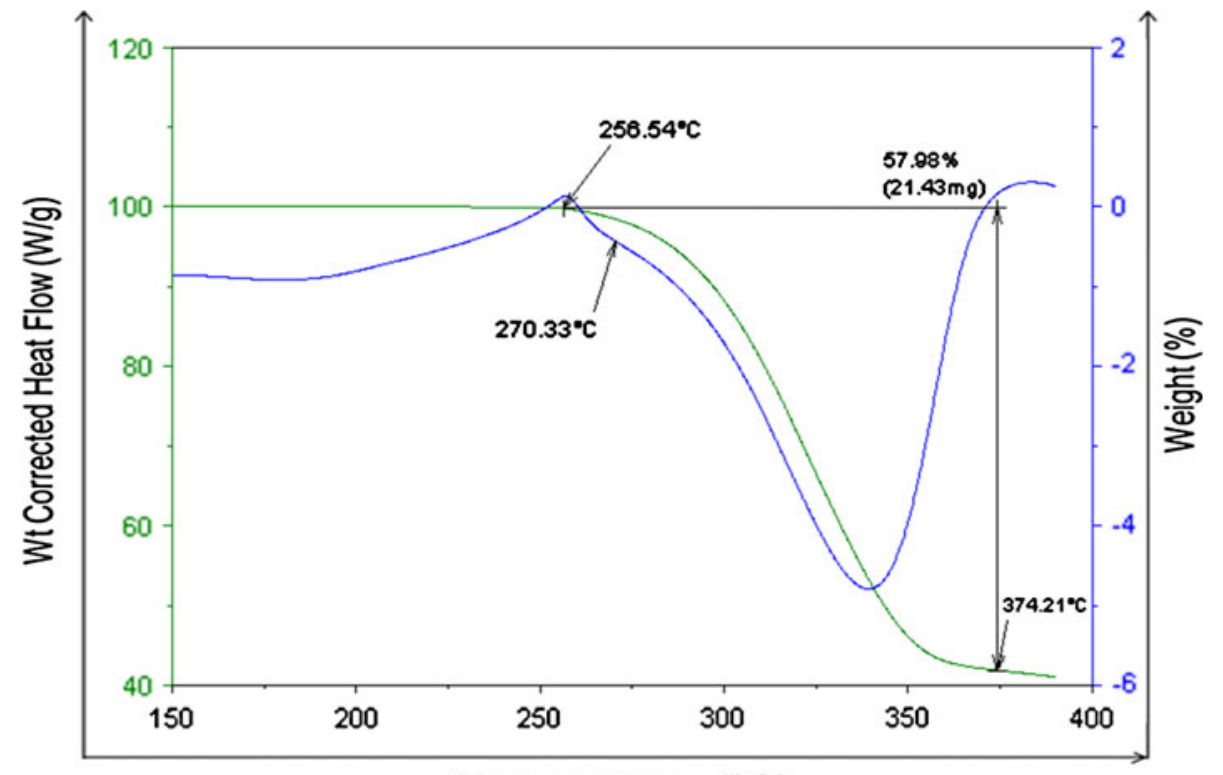

Temperature $\left({ }^{\circ} \mathrm{C}\right)$ 
Table 2 Comparison between the chemical composition (w/w \%) of PVC sample used and the carbonaceous residue obtained from pyrolysis at 300 and $340{ }^{\circ} \mathrm{C}$ by XRF

\begin{tabular}{lrll}
\hline & $\begin{array}{l}\text { Pure } \\
\text { PVC }\end{array}$ & $\begin{array}{l}\text { Carbonaceous residue } \\
300{ }^{\circ} \mathrm{C}\end{array}$ & $\begin{array}{l}\text { Carbonaceous residue } \\
340{ }^{\circ} \mathrm{C}\end{array}$ \\
\hline Carbon & 38.4 & 84.3 & 89.0 \\
Hydrogen & 4.9 & 8.9 & 7.0 \\
Chlorine & 56.7 & 1.7 & 0.07 \\
\hline
\end{tabular}

complete sample combustion, highlighting the interest in the use of the de-chlorinated fraction for energetic valorization.

\section{Pilot-Scale Validation of the Process}

Pilot scale tests were performed to validate the kinetic study performed in DTA/TGA experiments, which led us to conclude that the de-chlorination of PVC molecule occurs at $340{ }^{\circ} \mathrm{C}$. The plant was prepared to treat up to $500 \mathrm{~g}$ of residues. The all process consists in a sequence of two phases: the first one is the de-chlorination of PVC molecule (at $400{ }^{\circ} \mathrm{C}$ ) and the second one consists in the energetic valorization (at $800{ }^{\circ} \mathrm{C}$ ) of the carbonaceous residue obtained in the first phase with the synthesis gas production. An industrial PVC containing waste (Fig. 6) was used to validate the results obtained with pure PVC.

The residence time, for the two phases of the process $(\sim 160 \mathrm{~min})$, in the reactor was determined through the monitoring of pressure. The reaction starts in vacuum ( 0.5 bar below atmospheric pressure), increases during the process of gas releasing after which it starts to decrease. It is assumed that the reaction is completed when the pressure reaches the atmospheric pressure. During the reaction, a pressure of 0.5 bar (above atmospheric pressure) is the minimum required for the synthesis gas, produced

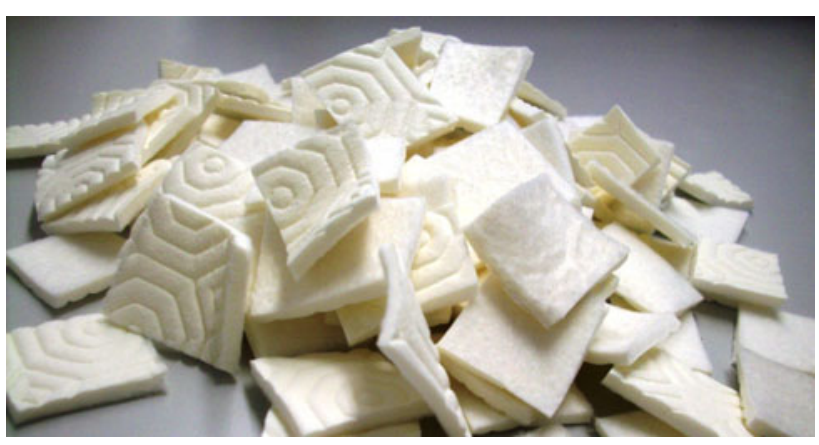

Fig. 6 Industrial PVC-containing waste used in the pilot plant tests

meanwhile inside the reactor, to be forced and bubble the $30 \mathrm{~L}$ of aqueous solution within the columns $2-4$ in Fig. 1 .

Figure 7 shows the temperature profile of the test for both phases. The first stage was carried out at $400{ }^{\circ} \mathrm{C}$ and with a heating rate of $20^{\circ} \mathrm{C} / \mathrm{min}$. The residence time of the residue in the reactor is approximately of $160 \mathrm{~min}$, being the time of each stage $80 \mathrm{~min}$.

During the first phase of de-chlorination of PVC-containing waste, the $\mathrm{pH}$ was measured in continuous in column 2, and the profile is presented in Fig. 8.

As it was already mentioned, the procedure is divided in two stages. The first stage is a low-temperature pyrolysis or carbonization, for the de-chlorination of the PVC-containing waste, where the released chlorine is recovered in the column in the form of hydrochloric acid, sodium chloride or calcium chloride. After the first stage is completed, a second stage takes place. When the internal pressure decreases to 1 bar it is assumed that the reactions, on phase one, were completed.

Afterwards, the carbonaceous residue resulting from the first stage is energetically valorized, by the increase of the
Fig. 5 DTA/TGA curve of carbonaceous residue heated up to $500{ }^{\circ} \mathrm{C}$

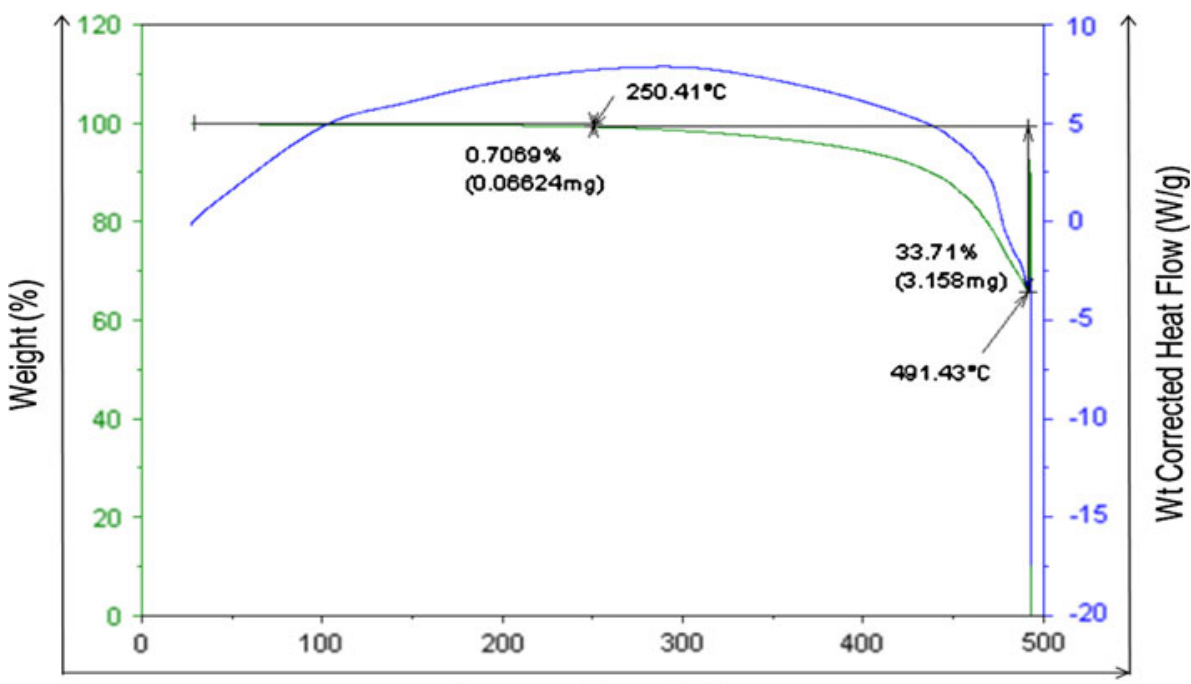

Temperature $\left({ }^{\circ} \mathrm{C}\right)$ 
Fig. 7 Temperature profile performed for the two stages of the process and for an initial residue charge of $250 \mathrm{~g}$

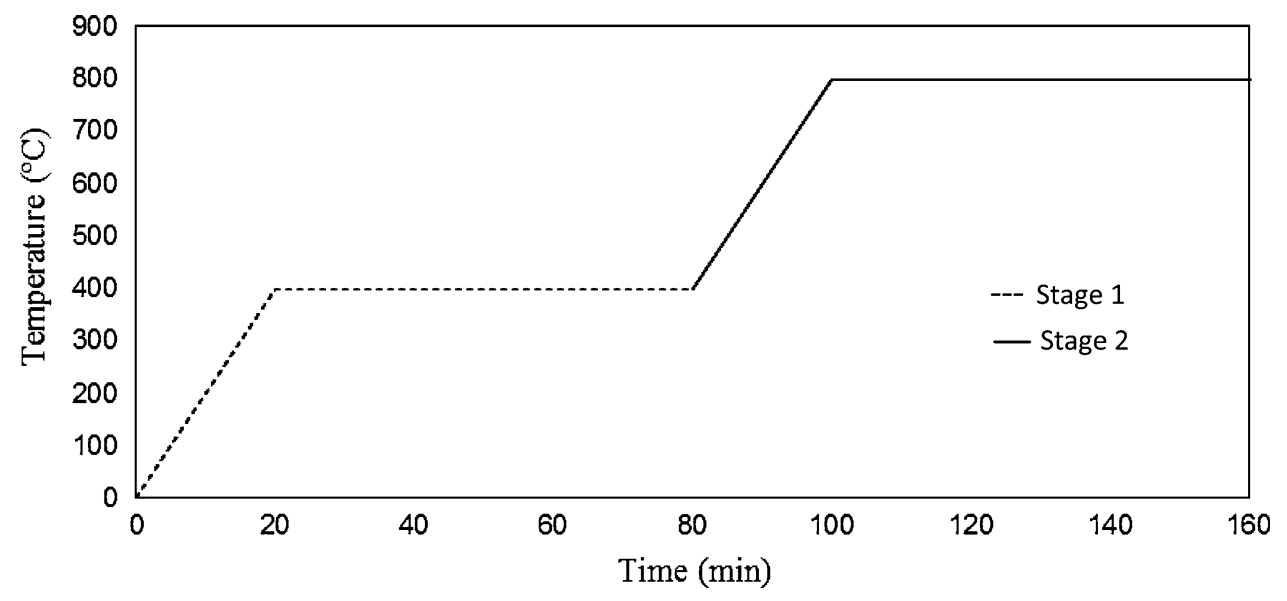

Fig. 8 Evolution of $\mathrm{pH}$ during the test of low temperature pyrolysis, first step that constitute a total time of $80 \mathrm{~min}$

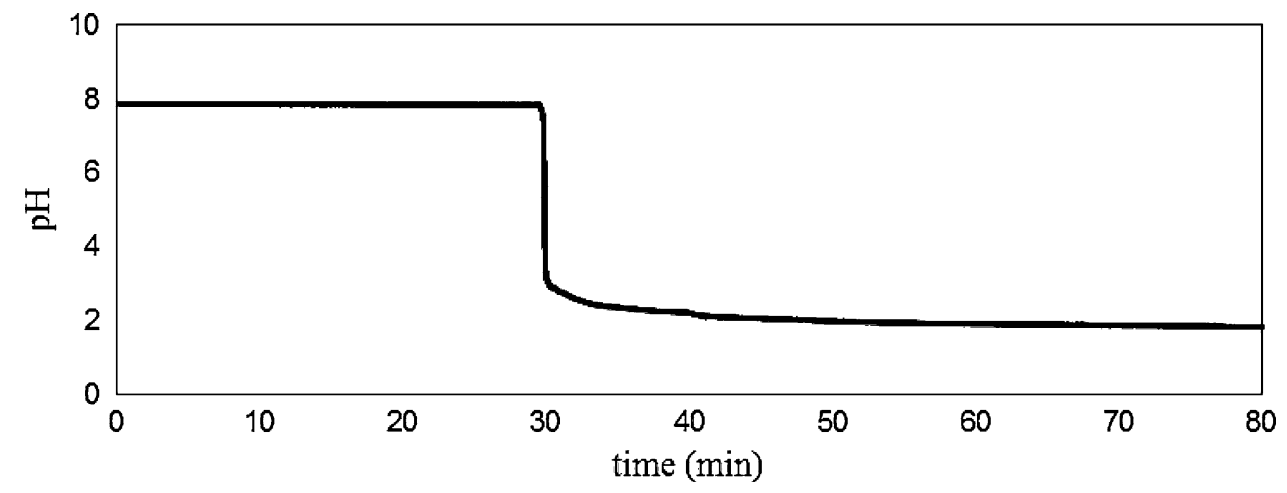

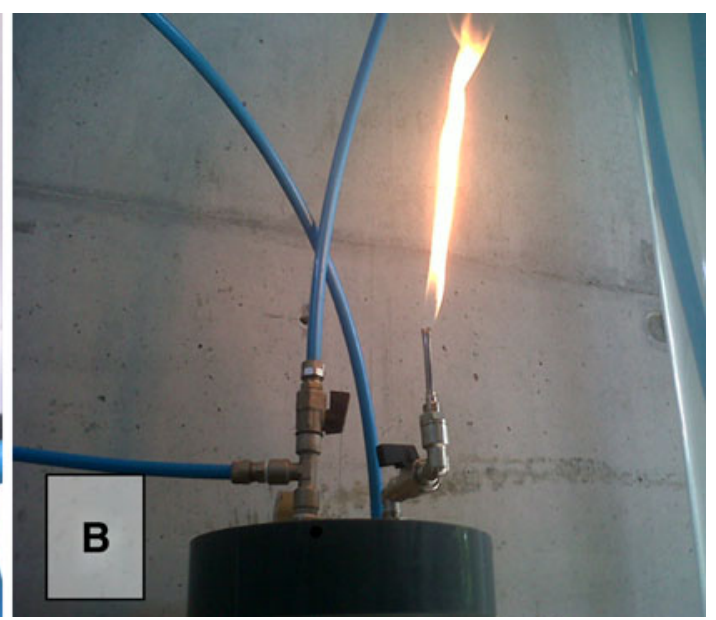

Fig. 9 Syngas burning (resulting from energetic valorization of the chlorine-free carbonaceous residue at $800{ }^{\circ} \mathrm{C}$ ): $\mathbf{a}$ directly and $\mathbf{b}$ after passing in the column

Table 3 Composition of the gas resulting from high temperature pyrolysis of the chlorine-free carbonaceous residue at $800{ }^{\circ} \mathrm{C}$, the remaining $15 \%$ corresponds to other hydrocarbons

\begin{tabular}{lc}
\hline & $\%(\mathrm{v} / \mathrm{v})$ \\
\hline Hydrogen & 40 \\
Carbon monoxide & 17 \\
Methane & 11 \\
Carbon dioxide & 5 \\
Steam & 12 \\
\hline
\end{tabular}

furnace temperature up to $800{ }^{\circ} \mathrm{C}$. The main reaction product is a synthesis gas with fuel power (Fig. 9), which may, after treatment, be used in substitution of natural gas or other fossil fuels. The produced gas is mostly composed of hydrogen, carbon monoxide and methane (Table 3).

The gas volume release on phase 1 and 2 was, respectively, of 21 and $29 \mathrm{~L}$ for an initial amount of residues of $250 \mathrm{~g}$. As a result of the treatment process in the first phase an aqueous solution of hydrochloric acid with a $\sim 2 \mathrm{pH}$ was obtained. 
Table 4 Characterization of the residue obtained at the end of the valorization test, by elemental analysis (TruSpec Elemental Determinator, model TruSpec CHN-Leco) and calorimeter (AC500 Calorimeter-Leco)

\begin{tabular}{ll}
\hline & Final residue \\
\hline Carbon $(\%)$ & 36.5 \\
Hydrogen $(\%)$ & 2.04 \\
Inorganic ashes & Rest for $100 \%$ \\
LHV $(\mathrm{J} / \mathrm{g})$ & 17,500 \\
\hline
\end{tabular}

Table 5 Energy cost for a full test in pilot plant

\begin{tabular}{lll}
\hline & Heating elements activation time $(\min )$ & Partial cost (Eur) \\
\hline Stage 1 & 20 & 0.26 \\
Stage 2 & 40 & 0.48 \\
& Total cost & 0.74 \\
\hline
\end{tabular}

After both stages were completed, $15.8 \%$ of residue (in $\mathrm{wt} \%$ ) remains within the reactor. This residue was analyzed to obtain its chemical composition (Table 4).

This final residue still has good characteristics to be used in energetic valorization processes at temperatures higher than those that were tested in the present study (Table 5).

To estimate the process treatment energetic costs, it was necessary to obtain the total time that the heating elements were activated in each stage. Knowing that the total power of the heating elements is $7,500 \mathrm{~W}$ and assuming that the price for $\mathrm{KWh}$ is $0.10 \mathrm{Eur}$, it is possible to estimate that the energetic costs of the all process treatment are of 2.96 Eur/ $\mathrm{kg}$ of residue.

\section{Conclusions}

In this work, the kinetics of the reaction of thermal decomposition of PVC were studied and led to the development of a kinetic model, with the expression ln $\rho=31.3-16.100 / \mathrm{T}+1.020 \ln \mathrm{C}(\mathrm{HCl})$. This model was obtained for decomposition temperatures lower than $340{ }^{\circ} \mathrm{C}$, in which almost all chlorine is removed from pure PVC through the chemical reaction described, with an activation energy of $133,800 \mathrm{~J} / \mathrm{mol}$.

It was demonstrated that a pyrolysis treatment at $340{ }^{\circ} \mathrm{C}$ is able to remove almost all of the chlorine present in the PVC-containing wastes, thereby facilitating the subsequent energetic valorization process to produce a synthesis gas with high energetic potential.

The chlorine release during pyrolysis treatment at $340{ }^{\circ} \mathrm{C}$ can be fixed in the form of an aqueous solution of hydrochloric acid, calcium chloride or sodium chloride, making this route attractive concerning environmental benefits, avoiding the deleterious effect of toxic compounds emissions to the atmosphere.

In order to validate the laboratory tests, a pilot plant was constructed to perform experiments using PVC-containing wastes from a local textile industry. A careful choice of the materials used is required to overcome the problems that might be associated with corrosion of materials, isolation and temperature maintenance inside the reactor and costs effectiveness. Entry and leakage control of gases must also be addressed, as on one hand, pyrolysis is a process that must occur in anoxic environment and cannot be contaminated with oxidizing agents, and on the other hand, the produced gases cannot leak to atmosphere, considering their toxicity.

Our results showed that in a complete test, for each $250 \mathrm{~g}$ of industrial waste, 50 liters of gas are produced, of which $29 \mathrm{~L}$ correspond to added value gas, being produced 11.6 L of hydrogen, 4.9 L of carbon monoxide and $3.2 \mathrm{~L}$ of methane.

It is possible to conclude that the implementation of the described process for the treatment/valorization of the PVC-containing wastes has many advantages as it promotes the generation of value-added products, namely concentrated hydrochloric acid, carbon-rich residue (carbonaceous residue-char) to produce heat and a synthesis gas for turbines or gas engines as a substitute of natural gas.

\section{References}

1. Lewis, F., Ablow, C.: Pyrogas From Biomass. Presented to a conference on capturing the sun through bioconversion, Washington, D.C., Shoreham Americana Hotel. Stanford research institute (1976)

2. Zevenhoven, R., Axelsen, E., Hupa, M.: Pyrolysis of wastederived fuel mixtures containing PVC. Fuel 81, 507-510 (2002)

3. Kim, S.: Pyrolysis of waste PVC pipe. Waste Manag. 21, 609-616 (2001)

4. Jaksland, C., Rasmussen, E., Rohde, T.: A new technology for treatment of PVC waste. Waste Manag. 20, 463-467 (2000)

5. Siddique, R., Khatib, J., Kaur, I.: Use of recycled plastic in concrete: a review. Waste Manag. 28, 1835-1852 (2007)

6. Al-Salem, S., Lettieri, P., Baeyens, J.: Recycling and recovery routes of plastic solid waste (PSW): a review. Waste Manag. 29, 2625-2643 (2009)

7. Takuma, K., Uemichi, Y., Ayame, A.: Product distribution from catalytic degradation of polyethylene over H-gallosilicate. Appl. Catal. A. 192, 273-280 (1999)

8. Spinacé, M., Paoli, M.: A tecnologia da reciclagem de polímeros. Revisão, Química Nova 28, 65-72 (2005)

9. Ma, S., Lu, J., Gao, J.: Study of the low temperature pyrolysis of PVC. Energy Fuels 16, 338-342 (2002)

10. Qiao, W., Song, Y., Yoon, S., Korai, Y., Mochida, I., Yoshiga, S., Fukuda, H., Yamazaki, A.: Carbonization of waste PVC to develop porous carbon material without further activation. Waste Manag. 26, 592-598 (2006)

11. Qing-lei, S., Xin-gang, S., Yun-liang, L., He, Z., Xiao, W., Chuan-ge, C., Jian-hua, L.: Thermogravimetric-mass spectrometric study of the pyrolysis behavior of PVC. J. China Univ. Min. Technol. 17(2), 242-247 (2007) 
12. Saeed, L., Tohka, A., Haapala, M., Zevenhoven, R.: Pyrolysis and combustion of PVC, PVC-wood and PVC-coal mixtures in a two-stage fluidized bed process. Fuel Process. Technol. 85, 1565-1583 (2004)

13. Blazevska-Gilev, J., Spaseska, D.: Formal kinetic analysis of PVC thermal degradation. J. Univ. Chem. Technol. Metall. 45(3), 251-254 (2010)

14. Tanaka, Y., Tsuji, T., Shibata, T., Uemaki, O., Itoh, H.: Dehydrochlorination Rate in Thermal Degradation of PVC. School of Engineering, Hokkaido University, Japan 060-8628 (2007)

15. Kamo, T., Yamamoto, Y., Miki, K., Sato, Y.: Conversion of waste polyvinyl chloride (PVC) to useful chemicals. Resources and Environment. 305, Japan (1996)

16. Ragazzi, M., Ischia, M., Dal Maschio, R., Rada, E., Grigiante, M., Baratieri, M.: Disposal of PVC by pyrolysis: characterization of the process and lab scale reactor tests. Proceeding Venice 2010. Third International Symposium on Energy from Biomass and Waste. (2010)

17. Karayildirim, T., Yanik, J., Yuksel, M., Saglam, M., Vasile, C., Bockhorn, H.: The effect of some fillers on PVC degradation. J. Anal. Appl. Pyrol. 75, 112-119 (2006)
18. Miskolczi, N., Bartha, L., Angyal, A.: Pyrolysis of polyvinyl chloride (PVC)-containing mixed plastic waste for recovery of hydrocarbons. Energy Fuels 23, 2743-2749 (2009)

19. Cheung, K., Lee, K., Lam, K., Chan, T., Lee, C., Hui, C.: Operation strategy for multi-stage pyrolysis. J. Anal. Appl. Pyrol. 91, 165-182 (2011)

20. Almeida, M., Castro, F.: Aços Para Cutelarias. Cadernos de Metalurgia $\mathrm{N}^{\circ}$ 1, CETEM, Braga, pp. 44-47 (1991) (in Portuguese)

21. Soares, P.: Aços: Características Tratamentos, 4th edn, p. 160 (1987) (in Portuguese)

22. Brydson, J.A.: Plastics Materials, 7th edn, p. 411. ButterworthHeinemann, Woburn (1999)

23. Castro, A., Soares, D., Vilarinho, C., Castro, F.: Kinetics of thermal de-chlorination of PVC under pyrolitic conditions. Waste Manag. 32, 847-851 (2012) 